\title{
LYDIA BRASILEIRA: A VELHICE DO SERTÃO E A PELEJA DECOLONIAL NA PANDEMIA
}

LYDIA BRAZILIA: THE OLD AGE OF THE SERTÃO AND THE DECOLONIAL STRUGGLE IN THE PANDEMIC

\section{Raquel Litterio de Bastos}

raquelitterio@gmail.com

Professora Adjunta na Escola Multicampi de Ciências Médicas (EMCM/ UFRN). Líder do Grupo de Pesquisa em Antropologia da Ciência e da Técnica - Caixa-Preta (EMCM/UFRN). Membro da Rede Humanidades Covid-19 - MCTI. Doutora em Saúde Coletiva.

ORCID: https://orcid.org/0000-0002-7556-7701

\section{Eduardo Neves Rocha de Brito}

edurocha.ant@gmail.com

Coordenador do Caixa-preta - Grupo de Pesquisa em Antropologia da Ciência e da Técnica da Escola Multicampi de Ciências Médicas (EMCM/UFRN). Doutor em Antropologia Social.

ORCID: https://orcid.org/0000-0002-6705-2302

\section{Jéssica Farias Dantas Medeiros}

fariasjessicad@gmail.com

Professora Substituta na Escola Multicampi de Ciências Médicas (EMCM/UFRN). Membro do Grupo de Pesquisa em Antropologia da Ciência e da Técnica - Caixa-preta. Mestre em Saúde Coletiva.

ORCID: https://orcid.org/0000-0002-8210-1344

\section{Raíssa Thamires Fernandes de Oliveira}

serimahtassiar@gmail.com

Membro do Grupo de Pesquisa em Antropologia da Ciência e da Técnica - Caixa-Preta. Vinculação: Escola Multicampi de Ciências Médicas da Universidade Federal do Rio Grande do Norte. Discente da graduação de Medicina.

ORCID: https://orcid.org/0000-0001-9868-5797

\section{(1) (1)(2)}

Esta obra está licenciada sob uma licença Creative Commons Attribution-NonCommercial-ShareAlike 4.0 International License.

\section{RESUMO}

O texto descreve as filmagens do documentário "Lydia mão-molenga brasileira", que versa sobre a última oficina de mamulengos da Mestra Lydia Brasileira, realizada no Sertão do Rio Grande do Norte, na cidade de Caicó, nos primeiros seis meses de 2021. Entre modelagens e tecidos, 
alegrias e tristezas, encontros e desencontros, o objetivo do artigo é problematizar o cuidado, a autonomia e o controle dos idosos considerados grupo de risco, em especial as mulheres sertanejas, na crise sanitária da covid-19. A narrativa se adensa a partir dos relatos da Mestra, no desenrolar da Oficina onde ocorre o documentário. Ainda na oficina, Lydia, com seus 84 anos, desenvolve o trabalho de relembrar a sua vida e os fatos que a oprimiram como mulher: primeiro, a infância em uma família sertaneja proprietária de terras destinadas à criação de gado, centrada em costumes patriarcais e eurocentrados; depois, o arranjo matrimonial com um violento militar, sua separação durante os anos de chumbo, o encontro com a arte dos mamulengos e a perda de autonomia durante a pandemia. A pandemia de covid-19 desnuda as práticas autoritárias de cuidado com as mulheres idosas.

Palavras-chave: idosas; covid-19; decolonial; sertão; mamulengo.

\section{ABSTRACT}

The text describes the filming of the documentary "Lydia Mão-molenga Brasileira", which addresses the last puppet workshop of the master craftswoman Lydia Brasileira, in the Sertão of Rio Grande do Norte, in the city of Caicó, in the first six months of 2021. Amongst models and fabrics, joys and sorrows, encounters and departures, the aim of the article is to discuss the care, autonomy and control of the elderly, considered a risk group, especially rural women, in the health crisis provoked by the Covid-19. The narrative becomes stronger based on the reports from Lydia, in the course of the Workshop where the documentary takes place. Still in her studio, Lydia, in her 84th year of life, develops the work of remembering her life and the facts that oppressed her as a woman; first, in childhood, in a family of farmers that owns land for cattle raising, centered on patriarchal and Eurocentric customs; then, on the marital arrangement with a violent military man, their separation during the Years of Lead, the encounter with the art of mamulengos and the loss of autonomy during the pandemic. The covid-19 Pandemic lays bare authoritarian care practices for older women.

Keywords: elderly; covid-19; decolonial; sertão; mamulengo.

\section{INTRODUÇÃO}

Final de tarde e a Artesania do Cuidar, disciplina eletiva da Escola Multicampi de Ciências Médicas de Caicó-RN, começaria. Além da habitual mística da educação popular, eu e a outra professora decidimos fazer uma performance: construímos cartazes de vestir, dois papelões atados por um barbante que servia de alça. De um lado estava escrito "conte-me uma história de amor", no outro, "conte-me uma história de 
dor". O mote do dia: “a escuta!". Buscamos, girando pela sala, alguém com muitas histórias. Entre os cabelos, encontramos um cabelo branco. Aquela mulher seria a ideal. Relutou ao ser escolhida, negou ter algo importante para contar e, por fim, contou: "Eu vivi em um casamento arranjado, minha família me casou com um militar. Esse militar me estuprou na nossa noite de núpcias, foi um estupro anal. Era um gay que não se assumia. Tive filhos, todos da mesma forma. Me separei durante o período da Ditadura Militar. Para não enlouquecer, eu fiz mamulengos - um boneco do tipo fantoche, típico do Nordeste brasileiro -, e abri as paredes do meu casarão para as crianças pintarem seus traumas”. Esse relato aconteceu no meu primeiro contato com Lydia.

Lydia Brasileira, mulher idosa, aposentada da carreira de professora da Universidade Federal do Rio Grande do Norte, dedicou parte de sua vida aos trabalhos de aprendizado, seja como docente, seja como mamulengueira; a mulher aprendeu a fazer mamulengo em Recife-PE. Instigava-nos a seguinte indagação: por quais razões uma mulher que dizia não ter nada para falar, proferiu um relato tão íntimo?

A pandemia se instalou e a disciplina parou. Apaguei da memória o episódio, todos se isolaram. Após cinco meses confinada em um apartamento, iniciei caminhadas noturnas na Ilha de Santana-RN, um espaço aberto para o lazer da população da cidade de Caicó-RN. No meio do caminho para a Ilha havia uma casa bordada, a casa de Lydia Brasileira. Em encontros esporádicos, encontros de calçada, passei a cumprimentá-la, e ela ainda lembrava meu nome, mesmo com a máscara para a proteção da covid-19 ocultando o meu rosto. Entre diálogos informais, enquanto eu a acompanhava na varredura da calçada, veio a notícia que mudaria nossos percursos: "meu filho está vindo morar comigo" - a felicidade era visível. Depois de algumas semanas o discurso e o semblante se modificaram: "meu filho, na verdade, veio me buscar para morar com ele em outro lugar".

O filho veio buscá-la para morar longe, Lydia ia deixar Caicó. Para ela havia só um lamento, o não fechamento do que tinha iniciado na Artesania, a oficina de mamulengos. Entre os verbos morar e buscar, Lydia não mencionava o cuidar. Na rotina tranquila e ativa, preservava sua autonomia. Incentivei então, mesmo sabendo de todas as implicações éticas da proposta, que fizéssemos uma filmagem para as gerações posteriores, pois aquela seria "a última oficina de Lydia mão-molenga brasileira”. Em meio à pandemia no sertão potiguar, o vírus não conseguiu interromper o trânsito dos saberes. A oficina seria a última, pois a mestra artesã estava partindo. Na proposta da oficina, os mamulengos enunciaram a agência de descortinar a problemática da mulher idosa no sertão na pandemia, emergindo situações e corpos encobertos pela lógica da colonialidade que os tornou menores e abjetos (PEREIRA, 2015).

O principal objetivo deste texto é tensionar as definições e as aplicações dos cuidados com as pessoas idosas na atual pandemia de covid-19, 
por meio do percurso de Lydia Brasileira. Especificamente, descrever e analisar nossos encontros que envolveram a idealização, organização e materialização de uma oficina de mamulengos, à medida em que ainda nos permitiram refletir sobre os corpos femininos e a colonialidade. A ideia aqui é levantar dados etnográficos oriundos de situações etnográficas com Lydia, criticar as certezas e as incertezas do mundo colonial em pandemia e enunciar a potencia criativa do Teatro de Mamulengos.

Para compreender a lógica da colonialidade, apoiei-me em estudos decoloniais tais como os de Santiago Castro-Gomez (2007), Ramón Grosfoguel (2002, 2007, 2008, 2012), Walter Mignolo (2000a, 2000b, 2008), Arturo Escobar e Walter Mignolo (2010), Catherine Walsh (2004, 2007, 2009), Rita Laura Segato (2013, 2012, 2014), Eduardo Restrepo e Axel Rojas (2010) e nas pesquisas que problematizam sobre o conceito de care (cuidado) e as reflexões quanto às questões de gênero e sua relação com a velhice. Pascale Molinier e Patricia Paperman (2015), em seu texto "Descompartimentar a noção de cuidado?", alertam que essa é uma região de confronto, presente nas relações entre colonizados e colonizadores.

Por sua vez, Debert e Pulhez (2019) também problematizam os desafios do cuidado em interface com as categorias relacionais de gênero, velhice e deficiência nos vínculos historicamente situados, em formas específicas e particulares, permeadas por uma lógica colonial, enquanto Tronto (1998) menciona que o exercício do cuidado está permeado por conflitos e relações de poder que se apresentam na seleção e na priorização das necessidades de uns sobre os outros. Os idosos são reconhecidos como um dos mais afetados, ao serem convertidos em "grupo de risco" durante a pandemia (DOURADO, 2020).

A Rede Humanidades Covid-19, coordenada por Jean Segata (2020), é também uma de nossas inspirações nesta investigação, pois instiga-nos à descrição e à análise dos cenários locais de pandemia e suas articulações com os processos de dominações em níveis globais. Este texto é sobre como a pandemia no Brasil profundo se deu de forma diversa para uma mulher idosa no Sertão de Caicó. Em sua narrativa compreende-se que "cada caso NÃO é um caso", o que torna relevante apresentar a narrativa desta Calungueira no Seridó Potiguar ${ }^{1}$.

Nas próximas páginas, é descrita a elaboração dos afetos em meio à preparação da oficina, o trânsito dos saberes e a crítica decolonial à visão de mundo patriarcal, costuradas em meio às categorias nativas que surgiram durante a oficina - que seria a última da interlocutora antes de ter sua autonomia cerceada -, no percurso do registro do ofício de construir

\section{O MAMULENGO}

Antes de se iniciar propriamente a descrição da oficina, situo brevemente o leitor sobre o que é um mamulengo. O mamulengo é o nome mais conhecido do Teatro de Bonecos Popular do Nordeste. Tradicio- 
nalmente feito de madeira, pano e cabaça, hoje se empregam também diferentes tipos de materiais, como papel e garrafas plásticas, entre outros materiais. Além da diversidade do material, existem muitos tipos de animação: o mamulengo pode ser movimentado por uma vara, por uma corda, manipulação direta e por luva, que é o método mais habitual em Caicó.

Caracterizado por apresentações teatrais divertidas, cheias de humor, o mamulengo é uma forma de expressão popular protagonizada por bonecos, tipo fantoches, muito comum no Nordeste brasileiro. O Teatro de Mamulengos, em 2015, foi reconhecido pelo Instituto do Patrimônio Histórico e Artístico Nacional - IPHAN como Patrimônio Cultural do Brasil.

São várias as versões sobre a origem desse folguedo, dessa brincadeira: ela está na memória popular, nas raízes afro-brasileiras. Mestre Ginu, bonequeiro pernambucano, contava que o mamulengo surgiu nas senzalas, onde o povo negro escravizado se reinventava para contar histórias de libertação, a partir de bonecos esculpidos em madeira. Era a dor transformada em alegria: cheio de humor, o boneco, sendo objeto, permitia o agenciamento da denúncia por ele protagonizada. Vale destacar que, nos diálogos que costuraram a oficina dos mamulengos, as palavras "fantoche" e "boneco", ambas de origem europeia (italiana e alemã, respectivamente), eram evitadas, em uma ação de não utilizar palavras coloniais e colonizadoras; Lydia estava ciente dos processos de dominação que estes termos carregam.

A expressão mão-molenga é oriunda dos espetáculos em que os bonecos eram portados em punho, daí a expressão mamulengo e as variações das expressões "mão mole", "mão molenga". Feito de madeira proveniente do mulungu, por causa da maciez, leveza e pela facilidade no ato de talhar, o mestre mamulengueiro não só cria as personagens como também lhes dá movimento. Em geral, os mestres aprendem e repassam a arte aos seus discípulos com o objetivo de não deixar o mamulengo cair no esquecimento.

Outro aspecto válido de ressaltar é que existiu uma oportunidade em que o Teatro de Mamulengos proporcionou que o público abandonasse a televisão para acompanhar as apresentações em praças públicas, como foi o caso da história do Museu do Mamulengo Espaço Tiridá, em Olinda-PE. Vale destacar que, além da diversão, o mamulengo tinha a função de informar as pessoas sobre inúmeras temáticas, desde avisos sobre acontecimentos da cidade até campanhas de saúde (SILVA FILHO; PACHECO, 2014). Este fenômeno, no entanto, não pode ser generalizado, uma vez que sabe-se que a tradição do Teatro de Mamulengo perdeu espaço para os meios de comunicação modernos, por isso a atividade é vista como um dos focos de patrimonialização do Instituto do Patrimônio Histórico e Artístico Nacional (IPAHN).

Uma prudência sobre como inserimos a temática dos mamulengos neste texto diz respeito à trajetória particular de Lydia Brasileira como 
mestra mamulengueira, desta forma, os mamulengos estão inseridos em situações etnográfica conosco e Lydia. Por sua vez, Lydia é reconhecida como mestra na rede de mulheres mamulengueiras em Caicó, no Rio Grande do Norte e em outras regiões. Então, este texto não tem o objetivo de descercar por completo a história, os conflitos, os usos, as apropriações e as diferenças deste universo vasto dos mamulengos. Trata-se mais de enunciar como esta arte é parte da mulher idosa que é Lydia Brasileira, atentando para as enunciações sobre os cuidados e a decolonialidade num mundo povoado por vírus e mamulengos.

Portanto, o teatro de mamulengos no Nordeste, para além de ser um patrimônio cultural, é também uma tecnologia complexa que envolve um leque de atores interagindo em uma rede de ações. Nas próximas linhas apresentarei o trabalho de campo e os desafios da etnografia em tempos de isolamento social.

\section{A OFICINA DECOLONIAL NO CASARÃO COLONIAL DE LYDIA BRASILEIRA}

Em janeiro de 2021, empolgada com a possibilidade deste encontro etnográfico, convidei outros pesquisadores, que partilharam da escrita deste texto, para compor a nossa equipe em campo. Mas a prudência reduziu a equipe a uma pessoa. Reuni então os apetrechos da filmagem, estudei sobre as técnicas de luz, desvendei os códigos da câmera, planejei o roteiro obcecadamente, mas sem grande sucesso na organização da execução técnica das filmagens. De forma amadora, iniciou-se a oficina e simultaneamente as filmagens. Raíssa, uma estudante de medicina interessada em tecer etnografias, acompanhou os dois primeiros encontros, e essa participação descortinou o encontro de mulheres de diferentes gerações. No entanto, havia uma preocupação extrema em redobrar a atenção sobre si para evitar contaminar Lydia com a covid-19 durante as filmagens. O protocolo de isolamento social exigia um rigor ainda maior e mais responsável, o que fez reduzir ao máximo a exposição de contato dentro e fora da oficina.

Mas qual história se iria contar na brincadeira? Lydia, aos oitenta e três anos, não era uma mulher de começar algo sem saber o destino final. Nada de gastar energia com o que não dará um resultado instigante ou relevante. Para os caicoenses, ela era uma dessas mulheres consideradas excepcionais, excêntricas, polêmicas, louca, triste ou $m a^{2}$, adjetivos dúbios e ineficazes para descrevê-la, para contê-la. A inspiração da estória emergiu ao longo dos encontros; seria “A peleja do negacionismo com o cientista!", temática que a equipe sentiu na rotina de Caicó. Estávamos, as três, Lydia, Raíssa e eu, eufóricas com a proposta do teatro e com a confecção dos mamulengos. Teríamos vários personagens: uma cientista negra, o negacionista, Lydia Brasileira por Lydia Brasileia, o vírus da covid-19 e sua mutação mirim. 
Na mise-en-scène, a peleja era contra o pensamento colonial e sua lógica de tornar o Outro um desqualificado, seja pela sua cor, seu gênero, sua posição social ou sua idade. No teatro de bonecos e no ethos privado, Lydia procurava privilegiar a cultura negra e indígena, o naturalismo e o movimento feminista. Em meio a crochetagem do trânsito dos saberes ancestrais, ela alertava a todos sobre a cultura embranquecida, violenta, racista e machista do vaqueiro do sertão, homem religioso, servil ao patrão dono das terras. Para o trânsito de saberes que eclodiu na convivência durante a oficina de Lydia, a definição que melhor descreve a fazedura decolonial é a que o antropólogo Pedro Paulo Gomes Pereira (2015) elaborou inspirado em autores ${ }^{2}$ citados na introdução deste texto: a ação de decolonizar está, necessariamente, em abrir-se aos Outros encobertos pela lógica da colonialidade que os torna inferiores.

Lydia, porém, teimava em usar a máscara de forma particular. Colocava-a sempre, mas, nas longas conversas que tivemos em sua cozinha, a proteção teimava em descer para o queixo. Eu a lembrava do perigo e ela me alertava para outros tantos. O perigo não era negado, mas relativizado frente aos anos de desventuras e batalhas que ela precisou travar para se tornar quem desejava ser. Consciente dos perigos dos privilégios que a destacavam na multidão, e sua responsabilidade de ser branca a fez forjar uma ruptura com a lógica patriarcal, com sua branquitude ${ }^{3} \mathrm{e}$ o poder de produzir subjetividade (SCHUCMAN, 2021). Sua situação econômica estável como docente aposentada da UFRN e sua tradição familiar colonialista eram negadas veementemente, apesar de indeléveis.

Atravessadas pelos protocolos de biossegurança, reunimos todos os materiais sobre a mesa branca da cozinha e passamos a interagir. No coração da casa e com a porta dos fundos, que leva ao quintal, aberta, entrava uma luminosidade ampla e incômoda, pois os pés de fruta não eram suficientes para conter o sol. Na bancada da cozinha sempre havia um cacho de banana e água. A mesa redonda, apertada contra a parede, estava coberta de coloridos rabiscos infantis. Versátil, a mesa também era apoio para as refeições. Próxima à mesa, a cozinha era emoldurada por uma grande janela de vidro que se abria para um jardim de inverno, que aqui no Sertão funciona como um respirador para canalizar o vento e tornar a casa mais fresca. Neste jardim, um pequeno chafariz branco, estilo colonial, desativado, ornamentava o espaço.

Lydia insistia em compartilhar uma refeição, mas, mesmo honrada pelo convite, isso nunca aconteceu. Os encontros eram de outra ordem. O medo de contaminá-la era imenso. Em torno da mesa, os tamboretes estavam ludicamente rabiscados. Unindo o fundo do casarão colonial com a entrada, havia um longo e escuro corredor que escondia as portas dos quartos, situados na parte de baixo. Nas paredes de todos os cômodos moravam pinturas, algumas com relevo de botões, pedras, brincos e tecidos. Maravilhada com as paredes, sentia-me em um museu de arte 
naïf, ou arte bruta. Lydia permitia que todas as crianças pintassem as paredes, do chão ao teto. Por vezes, caminhamos pela casa enquanto ela interpretava os desenhos que revelavam abusos sexuais.

Entre os desenhos, havia sua obra-prima: uma enorme cobra situada na parede central da entrada da casa. As cobras, e especialmente uma cobra gigante, compõem o mito local de que esse animal gigantesco estaria no Poço de Caicó e que sairia se não houvesse chuva no sertão. Saindo, o animal arrasaria a cidade. Na obra-prima de Lydia, a cobra penetra em um orifício, um ânus. Segundo a sua explicação, a obra era recente, feita em 2019, pois só então teve coragem de retratar os contínuos estupros em seu casamento.

Para ascender ao andar superior, uma moderna escada de madeira e metal em formato de "L". A subida era evitada por Lydia, tanto quanto conseguia. Exigia muita energia, não que esta lhe faltasse, mas era regrada. No mesmo andar, a máquina de costura imperava e, apesar de já não ser tão utilizada, estava em perfeito estado de conservação, com uma manutenção impecável.

O casarão bordado havia sido reformado para se tornar novamente habitável e, apesar da arquitetura colonial, apresentava ares de modernidade no seu interior. Parte do pagamento da reforma foi uma permuta com a divisão do casarão em duas partes. A segunda parte havia se transformado no escritório do arquiteto responsável pela reforma. $\mathrm{O}$ casarão está localizado em um local nobre da cidade de Caicó, na praça da Igreja de Santana. Na festa anual dedicada à padroeira, que já não é realizada há dois anos em decorrência da pandemia, há uma disputa por lugares bem localizados e centrais da praça. Pagos a preços elevados, situam os festeiros de acordo com o seu status social. Os que são considerados de maior relevância social, montam suas mesas nas calçadas de suas casas. Na maior parte, são médicos e advogados nascidos em Caicó e que retornam somente para participar da festa, em uma mistura de agradecimento e ostentação. Os espaços na parte de frente da nave da Igreja são os mais disputados e dão legitimidade para quem os ocupa. $\mathrm{Na}$ parte de trás da igreja estão os que querem participar da festa, mas não gozam da mesma posição. Festa branca, das pessoas às roupas. Os negros servem e disputam o espaço comercial, na oportunidade de vender pequenos petiscos e lembrancinhas da padroeira.

$\mathrm{O}$ arquiteto responsável pela reforma, também inquilino, pintou na parede do casarão as rendas da cidade. Os doces e as rendas são o orgulho da população, segundo o lema popular: "o bordado de Caicó não tem avesso”. Não há espaço para o erro! O Seridoense é altivo, reconhecido pelo porte e pelos olhos claros herdados dos holandeses ${ }^{3}$. Apesar da localização, por dentro a casa não ostentava luxo. Os móveis eram simples e de madeira, sem contornos requintados. Camas, cadeiras e armários pequenos, despojados de grande conforto e beleza. Na concepção naturalista de Lydia, a casa funcionava como uma extensão dos 
seus ideais, e, por isso, a estética minimalista. O luxo era não ter nada. No detalhe, os pequenos pedaços de pano colorido entre os ferrolhos da rede na tentativa de silenciar o ranger da maquinaria. Lydia fez questão de explicar como não incomodar os demais com os barulhos do cotidiano oriundos da casa.

Durante a oficina dos mamulengos, entre uma técnica e outra, uma discussão sobre a historicidade dos tipos de massa. Por constatação, a empiria demonstrava que o papel higiênico, mais barato, sempre era o melhor. Picar em pedaços bem pequenos é para os jovens, Lydia os desmantelava até terem uma aparência menor: como estava sendo filmada, caprichou um pouco mais naquilo que já não tinha mais paciência de fazer com perfeição. "Não existe essa coisa de errar". Como em um tutorial, ela já tinha uma porção de massa pronta. Havia encenado o preparo para nos mostrar. Muito didática, pedia que repetíssemos a ação para confirmar a fixação do aprendizado. O rolo de papelão que sustentava o papel higiênico ao seu entorno era de grande importância. Ele se tornaria o suporte da cabeça do mamulengo. Nada deveria ser desperdiçado no processo.

Empolgada, intercalava as falas da oficina com o rememorar dos fatos de sua história. Falou sobre a forma como a sua massa de mulher foi forjada e de como foi educada em uma estética francesa, patriarcal, coronelista e colonialista. É vista como polêmica por alguns e espetacular por outros, mas isso somente depois que envelheceu; quando jovem, desejou poder escolher a estampa do próprio vestido, não ser cordial com todas as visitas - fingindo costume, como se diz na cidade -, namorar sem casar e desacreditar de deus. Branca e de família tradicional, Lydia se orgulhava de ter ancestralidade. Sua avó foi uma das inúmeras mulheres Cariris que foram massacradas no Rio Grande do Norte ${ }^{4}$. A história de que sua avó também havia sido estuprada e gerado vários filhos foi repetida inúmeras vezes.

Ao dar o formato das cabeças dos mamulengos por meio da técnica do pó de serra envolto em um tecido, Lydia foi nos falando, para mim e Raíssa, sobre como a pandemia e sua vida se relacionavam:

Meninas, primeiro vocês cortam um pano quadrado, eu compro aqueles vendidos na feira de sábado, aqueles que são vendidos no chão da rua. Depois coloco pó de serra no centro do tecido e amarro tudo com corda. Vou mostrar como se faz, caso vocês estejam sozinhas. Sabe, quando a pandemia foi anunciada e todos correram para se isolar em casa, algumas pessoas ficaram preocupadas se eu ia sentir solidão. Solidão, que nada! Eu converso com os mamulengos, passo horas falando com eles, nem percebo o dia passar. Se tem uma coisa que eu não sinto é solidão. Mas agora, meu filho caçula veio me buscar. Eu fiquei feliz. Parece que eu não posso mais morar sozinha, bobagem! (risos). Ele vai morar comigo por uns tempos. 
Retomando a oficina, a Mestra Calungueira demonstrou como devemos assentar o pó de serra no tecido para dar um formato mais semelhante ao de uma cabeça. Demos tapas no embrulho redondo até chegar ao formato oval. Sobre o tecido, colocamos a massa com a ajuda de um pouco de água. As velhas facas sem corte funcionaram como espátulas e nos ajudaram a tornar lisa a massa em contato com a superfície do tecido. Para cada personagem, um nariz, uma orelha, uma face que traduza o objetivo do mamulengo na animação. A posição dos olhos é fundamental, mais próximos dão um ar infantil, mais distantes, olhos de um adulto. $\mathrm{O}$ nariz empinado é soberba, o mamulengo do negacionista ganhou um bem pontudo. A cientista, olhos enormes e cabelos pretos de espiral de caderno. Entre os processos de construção, risos e lágrimas de três gerações de mulheres que se reconheciam nas histórias de opressão feminina, cada qual no seu tempo.

Com a modelagem feita, era hora de assar as cabeças. No passado, rememora Lydia,

Fazíamos a massa de farinha e secávamos a massa ao sol. Dava um trabalhão, juntava barata depois de um tempo de armazenamento. Em dias chuvosos, a massa da cabeça demorava até dois dias. Eu esquecia e depois tinha que sair correndo para buscar a cabeça antes de perder todo o trabalho. Com o tempo, passei a fazer com papel higiênico e a secar no forno comum. Muito mais fácil! (risos).

Enquanto as cabeças secavam no forno a gás, subia um cheiro de algum produto químico presente na composição da cola branca utilizada na massa. A posição de subalternidade que Lydia expressava parecia ser inerente aos seus adoecimentos mentais. Ambos, a subalternidade e o adoecimento mental, eram a tônica do diálogo que parecia se misturar com o cheiro forte da química, como se a cena tivesse um odor fétido advindo das torturas que os papéis sociais causaram na interlocutora. Lydia narrou como havia pilhado as joias da família para custear seu tratamento psicológico.

Eu me apropriei duas vezes das joias da família. A primeira vez eu peguei um crucifixo cravejado de rubis, caríssimo! E paguei a minha terapia por anos. Já recuperada e separada do meu algoz, furtei novamente pedras, brincos e colares e os enterrei em um lugar que jamais revelarei. Devolvi para a terra o que é da terra. Foi um escândalo na família. Eu sei que fiz a coisa certa. Se eu não tivesse feito a terapia, eu teria enlouquecido com o sofrimento.

Como se diz aqui em Caicó, pronto!, a massa havia secado e podíamos passar para os próximos passos. Era hora de esvaziar a cabeça dos futuros mamulengos. Para isso, desatamos os nós que fechavam o tecido que continha o pó de serra e, com delicadeza, o sacudimos e demos leves tapinhas, até não sobrar nada dentro da cabeça. Com uma tesoura de ponta, iniciamos a retirada do tecido. Por vezes, algumas partes da massa saiam junto com o tecido, mas ela sempre tinha um conselho que 
nos orientava para o entendimento de que para quase tudo havia concerto. Para ela, a confecção do mamulengo é como a condução da vida, os erros são tão importantes quanto os acertos. O importante era não se amedrontar com o desafio.

Enquanto colocávamos o pescoço de papelão oriundo do rolo do papel higiênico, a mestra dos mamulengos nos contava sobre a dor de perder dois filhos pequenos, ambos da mesma forma, atropelados na calçada por um carro desgovernado. Decidimos, eu e Raíssa, que era o momento de desligar os equipamentos de gravação e apenas ficarmos juntas neste trabalho de lembrar fatos importantes que atravessaram a sua existência. O documentário tornou-se secundário ao que estava acontecendo conosco naquele encontro etnográfico.

Desta forma, chegamos a alguns consensos sobre as características dos personagens, o conteúdo da narrativa contada pelos mamulengos e as conexões com o contexto de biossegurança e negacionismo científico. As cores das tintas romperam o silêncio das tristes lembranças e nos debruçamos animadas sobre a pintura da pele dos personagens, dos contornos das bocas e dos olhos. Lydia se entusiasmava com as nossas sugestões, ao mesmo tempo que mantinha sua autoridade de mestra. A cientista do teatro precisa ser negra, o negacionista um branco, a estória precisava problematizar a realidade de exclusão étnico-religiosa do Seridó, a denúncia era o mote. O teatro não era brincadeira. Os textos e os roteiros sempre foram destinados às mãos de Lydia. Seus escritos possuem o constante objetivo de promover uma educação decolonial. Nada de falar de vaqueiros, couro, santos e procissões ou outros assuntos que considerava menores. A roteirista se concentrava em temas da ancestralidade local: a Caapora ${ }^{5}$, por exemplo, era considerada sua própria entidade totêmica, que permitia estabelecer uma comunicação mais estreita com a natureza. Lydia comentava animada que a entidade já havia se apresentado a ela em determinada oportunidade e descrevia a atmosfera que as envolveu, no entanto sem detalhar a sua experiência com a entidade.

\section{A CAMISOLA DO MAMULENGO}

Nos demais dias, Raíssa não pôde mais participar, as aulas remotas na Escola Multicampi de Ciências Médicas haviam voltado. Também, por questões de segurança, a equipe se reduziu a uma única pessoa. Pendurada de tralhas para o documentário, abandonei paulatinamente as filmagens e me concentrei no caderno de notas.

Os encontros se tornaram conversas íntimas acompanhadas de longos silêncios. Me sentia privilegiada a cada sequência de silêncios. Quando separadas, Lydia continuava a produção, alterava os narizes de lugar e avançava na proposta. Um documentário não é capaz de registrar essas pausas. A mestra dos mamulengos tinha o seu próprio ritmo. Foi nesta parte da oficina que ela reforçou que sua partida estava che- 
gando: "Meu filho quer me levar embora de Caicó". Então, não podia perder um segundo: o desperdício da vida é privilégio dos jovens.

A costura da camisola dos mamulengos proporcionou outra espécie de relação. No dia de coser, alinhamos nossas ancestralidades. Lydia me convidou para ir ao segundo andar do casarão, onde ficava a máquina de costura. Subimos passo a passo a escadaria de madeira que rangia denunciando nossa chegada a outro patamar. A máquina, uma antiga da marca Singer, estava completamente conservada, lubrificada e protegida. Lydia sentou em sua cadeira amarela e colocou-se a me ensinar como passar a linha pelas engrenagens da máquina. Depois de alguns segundos, indagou: "Você sabe costurar?" Eu respondi que sim, minha avó materna havia sido costureira a vida toda. Nas tardes que eu passava com ela, quando minha mãe não podia estar comigo enquanto trabalhava como telefonista, ela me ensinou a arte da costura. Com o avançar da idade, o mal de Parkinson a impedia de passar a linha pelo buraco $\mathrm{da}$ agulha e isso a aborrecia. Lydia se comoveu e pediu que eu fizesse o mesmo por ela naquele momento. Nos últimos dias, antes de partir de Caicó, eu pedi a Lydia para comprar sua máquina e ela me presenteou com a mesma, dizendo que confiava em mim.

Atreladas a este laço de confiança, a mestra passou a relatar os desconfortos em ser tratada de forma infantilizada ou como um ornamento extraordinário da cidade. Em um tom de incômodo, comentou:

As pessoas chegam até você e dizem - ai que fofinha essa velhinha, eu vou te ajudar Lydia - eu sou só uma mulher que envelheceu, não sou uma criança e não quero ser tratada como a avozinha de todos. Isso me é constrangedor, eu estou bem, sozinha com os mamulengos. Não sou fofinha. Gostei muito que o meu filho está aqui comigo, foi uma das coisas boas da pandemia, mas não gosto como algumas pessoas de Caicó me tratam, como se eu fosse uma pessoa importante. Eu detesto tudo isso. Eu só quero ser eu na minha versão idosa, ateia, polêmica, centrada na minha ancestralidade indígena, sem status, sem glamour e sem a obsessão dos outros em cuidar de mim na pandemia. As pessoas criam uma expectativa opressora sobre como uma mulher idosa deve ser e sentir. Eu não gosto disso, eu fujo disso desde que sou criança. Ser uma mulher velha e sozinha no sertão é uma afronta à sociedade colonialista e coronelista. A peleja é grande!

Sobre a camisola, o arranjo das estampas exigia sofisticação no olhar. A combinação precisa do tecido com a aparência do mamulengo podia levar o personagem ao sucesso total ou ao fracasso nos palcos. $\mathrm{O}$ acordo e a desarmonia entre as estampas, cores e texturas era um verdadeiro tratado estético. O local da aquisição também apresentava sua relevância. Quanto mais popular o local, mais próximo aos princípios de não gastar dinheiro com a brincadeira. Em Caicó, os tecidos são vendidos, aos sábados, no chão das ruas do comércio. Mas a aglomeração era grande e nunca fomos juntas ou fizemos uma imagem. Contudo, o 
molde era simples, elementar. Uma camisola com amplos espaços para caber mãos pequenas e mãos grandes, as mãos molengas. As estampas a lembraram das combinações que não podia usar porque sua mãe não a permitia.

Minha mãe achava chique que a gente tocasse piano, falasse outra língua e seguisse a estética francesa. Eu não podia escolher as estampas das minhas roupas. Era proibido! Então eu a rasgava, mesmo que eu ganhasse, para afrontá-la e, depois, eu usava os meus piores trajes. Ela queria me ensinar como receber as pessoas em casa. E eu, não! Até hoje acho um abuso a lembrança de que ela separava as melhores louças e comidas para dar às visitas. Comidas, inclusive, que não podíamos comer porque era para as vi-si-tas! Eu sempre detestei etiquetas. Eram todas perversas com as mulheres; eram de uma violência com tudo que não era europeu, rico e branco. Aqui em Caicó, quando alguém se oferece para comer na minha casa, eu logo digo não. Não quero desempenhar essa cordialidade em minha vida. Eu sou neta das mulheres indígenas estupradas pelo colonizador do Seridó, sou branca de desgosto, minha alma é negra. Desprezo a minha branquitude.

Segundo os estudos de Oliveira (2017, p. 28), as mulheres sertanejas republicanas recebiam uma "pedagogia materna" que sugeria uma forma de comportamento que se alinhasse ao ideal de progresso nacional, habitualmente publicado como norma de conduta nos jornais locais, solicitando das mesmas ponderações nas condutas e costumes femininos. Apesar de um tom de arrojo moderno ao reconhecer a importância feminina na sociedade sertaneja, tais "mulheres deveriam permanecer submissas e subservientes aos seus maridos e filhos, no caso desses últimos servindo-os e ao mesmo tempo lhes ensinando acerca de seus lugares sociais e, consequentemente, de gênero". Lydia reconhecia, por exemplo, que havia tido mais liberdade do que a mãe, que sequer havia tido a possibilidade de namorar antes de assumir o casamento arranjado. No caso da interlocutora, ela havia namorado o marido escolhido, no entanto, não desejava se casar com ele após reconhecer traços de violência em seu comportamento.

\section{A BRINCADEIRA}

Estando os mamulengos devidamente vestidos, era necessário alinhavar com a narrativa. Fizemos dois textos, um da mestra e outro meu, ambos com a mesma temática, e depois os confrontamos para uma escolha acertada. O texto que redigi era engraçado, tinha algumas falas entre os vírus e uma cena de correria no final. Ajustei as falas para as categorias nativas, temendo revelar o meu paulistanês. Lydia leu e disse de forma austera: "não gostei". Era um assunto demasiado sério para ser conduzido com risos. Sobre a linguagem, considerou desnecessário usar o palavreado local, a brincadeira tinha sempre que ser de denúncia e sua linguagem deveria ser capaz de alcançar qualquer público. Acostuma- 
da a construir os roteiros, modificou a narrativa, mantendo os mesmos personagens, de um dia para o outro. Estávamos prontas para a brincadeira.

A mestra calungueira me apresentou às ferramentas necessárias para o teatro de mamulengos. Além de uma cortina confeccionada com um tecido claro arrematado com pequenos tecidos coloridos no entorno, haviam também tamboretes - pequenos bancos de madeira de diferentes alturas - que permitiam que os brincantes, as mestras mamulengueiras, ficassem todos em um mesmo nível, homogeneizando todos independente dos seus tamanhos. Na parte da frente da cortina, em letras de tecido colorido, a frase "A Tecnologia do Mamulengo".

O teatro de animação ou teatro de formas animadas é entendido como uma arte que, quase sempre sem restrição de faixa etária, anima (dá alma) máscaras, bonecos, sombras e/ou objetos em mediação com o ator-animador (FEDERICI, 2017). É na passagem do inanimado para o animado, através do movimento que se dá pela manipulação coordenada pelo ator, que uma outra forma de existência manifesta a ilusão de vida, como lembra Ana Maria Amaral (2005, p. 17), acrescentando que "a energia que se desprende da matéria cria uma força que a transcende. Por isso, se diz que no teatro de animação existe magia, pois a magia surge quando acontece a ligação entre duas realidades opostas" (AMARAL, 2005).

Para a brincadeira acontecer e encerrar a última oficina, precisávamos de mais três pessoas, afinal eram cinco personagens. Entretanto, a pandemia não nos permitia essa extravagância. Entre os convidados, surgiu o nome de Catarina Calungueira, pedagoga envolvida com o teatro de mamulengos, pesquisadora sobre as mulheres brincantes e uma antiga orientanda de Lydia, empenhada em reunir todo um acervo para as gerações futuras. No mesmo período, Catarina havia sido contemplada por meio da Lei Aldir Blanc para organizar um festival de mulheres calungueiras do Sertão, em um canal do youtube. Lydia iria ser uma das homenageadas e apresentada em uma live. No festival, várias mulheres brincantes iriam apresentar seus mamulengos e um teatro de animação. Fomos então convidadas a apresentar o teatro que estávamos organizando, intitulado "A peleja da cientista com o negocista".

Os olhos de Lydia brilharam com a oportunidade e organizamos um ensaio das quatro brincantes, Lydia, eu, Catarina e Jéssica, da Artesania do Cuidar, respeitando os protocolos de segurança para não nos contaminarmos. Inclusive, os próprios personagens utilizam máscaras, menos o negacionista, que, por razões óbvias, se apresentava com a máscara pendurada na orelha direita, porque a esquerda ele havia amputado para evitar escutar os argumentos contrários.

É importante destacar que, segundo Balardim, Recio e Oliveira (2020), a parte de apresentação da brincadeira é uma atividade historicamente masculina. As mulheres foram restringidas à confecção dos 
mamulengos, ao passo em que a arte da brincadeira sempre foi um ofício masculino; porém, esta estrutura vem sendo modificada. A história e as pesquisas sobre as mulheres bonequeiras se desenvolve, para Balardim, Recio e Oliveira (2020), cercada de um dúbio sentimento em questões que envolvem a representação, a participação e o ativismo da mulher na arte popular e um tanto de tristeza na impossibilidade de dar visibilidade a todas as artistas e pesquisadoras que trabalham com os mamulengos.

Para a pesquisadora Silvia Federici (2017, p. 27), a história das mulheres "significa não somente uma história oculta que necessita se fazer visível, mas também uma forma particular de exploração e que [...] se deve reconsiderar a história das relações capitalistas". Seu estudo confirma que a reconstrução da história das mulheres, ou "o olhar sobre a história por um ponto de vista feminino, implica uma redefinição fundamental das categorias históricas aceitas e uma visibilização das estruturas ocultas de dominação" (FEDERICI, 2017, p. 29). A origem da palavra "marionete" carrega consigo uma interpretação dúbia. Do francês "marionnette", que provém de petit Marie (pequena Maria), sugere uma estratégia de manipulação. Entretanto, o termo utilizado no Nordeste é oriundo de outro universo, como já mencionado no início deste texto.

Se a preparação e a apresentação dos mamulengos carregam as marcas da segregação entre homens e mulheres no sertão, como também é uma relação de poder que vem sendo modificada, é possível entender o percurso de Lygia, os nossos encontro e a "A peleja da cientista com o negocista" como pontos sobressalentes destas estruturas que demonstram algumas fissuras.

Sendo assim, dando seguimento à preparação de nossa apresentação, marcamos o ensaio bem cedinho no domingo. Estendemos o tecido que servia de cortina para o teatro, vestimos os mamulengos e iniciamos a passar o texto da estória. Entre as falas e as filmagens, risos e mais risos. Lydia havia se arrumado para o evento. Vestia uma saia de renda branca e uma camiseta estampada com o rosto da vereadora e ativista negra Marielle Franco, que se tornou um símbolo mundial de resistência. Cada qual assumiu o seu personagem, ou será que foi o personagem que nos invadiu?

Catarina, a calungueira mais experiente, colocou-se a fazer vozes e criar frases de improviso. A atmosfera que nos envolvia era leve, fresca como aquela manhã, ao mesmo tempo que era reflexiva, implicada com as questões sociais que estavam ocorrendo no Brasil. Catarina mencionou então o quanto o mamulengo se tornava o alter ego dos calungueiros. Contou de um bonequeiro específico da região do Seridó que era um mulherengo na vida real e também o seu boneco o era.

Em meio ao ensaio, Lydia teve uma clareza súbita sobre o momento. Para ela, o encontro que antecede a brincadeira é terapêutico, pois, ao vestir o personagem, era possível falar de si por meio do mamulengo. 
Na brincadeira, não havia separação entre humanos e não humanos. Os que animavam os "mão-molengas" estavam também animados por eles. Um animismo, uma fronteira porosa entre nós e as outras formas de existir.

Para Sophie Houdart (2015), os não humanos, mais do que objetos ou dispositivos técnicos, são possuidores de sua própria palavra e dizer na relação e jamais predeterminados, tendo também uma existência permeada de incertezas, dúvidas, indecisões, imprevisibilidades, negociações e margem de manobra, tanto quanto em uma relação entre humanos. Articulá-los causou em nós um efeito de desestabilização na relação entre um humano e um não humano e entre os limites ontológicos dessa interação. O que estava em jogo na brincadeira era o que um e outro definiam em sua essência.

A brincadeira saiu do ensaio e subiu ao palco. Entre risos mascarados, esquecemos por alguns segundos as aflições nacionais, as violências vivenciadas, os medos. E, quando terminamos, Lydia nos confessou, um pouco inibida, mas feliz, que era a sua primeira vez atuando no teatro. O seu percurso esteve sempre voltado para a elaboração dos textos e a confecção dos mamulengos, jamais havia brincado.

\section{“MEU FILHO VEIO ME BUSCAR!": CARE E PODER}

Caminhando para a finalização do texto, é prudente tecer algumas considerações sobre a cena etnográfica e sua relação com o momento da pandemia. Os idosos, população com mais de sessenta anos, foram reconhecidos como os mais afetados na primeira fase da pandemia e, automaticamente, convertidos em "grupo de risco" (DOURADO, 2020). A categorização "grupo de risco" permanece presente no imaginário social para fazer referência a quem vive com HIV/Aids, e passou a ser imprimida aos idosos. Neste último ano, os estudos sobre envelhecimento foram impactados pela conversão dos idosos em "grupo de risco", gerando desdobramentos no emprego dessa classificação na revalidação de imagens estereotipadas da velhice. A mesma autora destaca o quanto o fenômeno da crise sanitária impactou as pesquisas realizadas nas ciências humanas e sociais (TONIOL, 2020; SEGATA, 2020; CARRARA, 2020), principalmente nos estudos sobre o envelhecimento, temática que é cara a este texto, levando os pesquisadores do campo a se posicionarem contra os estigmas que envolvem essa fase da vida que foram reforçados no cenário pandêmico (HENNING, 2020; DEBERT; FÉLIX, 2020; BELTRÃO, 2020; PAIT, 2020; DOURADO, 2020).

Simone Dourado (2020) parte da perspectiva de que a pessoa idosa deve ser o agente social protagonista do processo de envelhecimento populacional e deve ser considerada a partir de sua inserção em um mundo por ele conquistado. Entretanto, as pesquisas realizadas na Índia, sobretudo na literatura e nas práticas gerontológicas, são por vezes promotoras do apagamento da pessoa idosa (COHEN, 1992, p. 67), 
dando espaço às práticas "velhofóbicas” (GOLDENBERG, 2020). A determinação simplista de que eles são frágeis e devem ser tutelados pelo estado, sociedade e famílias reproduz a imagem da velhice como uma fase de perdas, principalmente de autonomia para tomar decisões, e de custos, considerando-os um dos maiores gastos do sistema de saúde (DOURADO, 2020).

A organização da crise sanitária no Brasil aponta para um cenário caótico e instável em decorrência do Ministério da Saúde, durante o governo do presidente Bolsonaro, não reconhecer as questões que se referem ao envelhecer em uma sociedade marcada pelo pertencimento ao mundo do trabalho e recortada pelas questões de gênero (BEAUVOIR, 1990; BOSI, 2010; DEBERT, 1997), desconsiderando que as mulheres idosas são permeadas por condições econômicas, sociais e regionais, como a narrativa da mestra calungueira Lydia Brasileira demonstra, tornado-as, assim, abjetas e apagando suas histórias.

A obra incontornável organizada por Debert e Pulhez (2019), intitulada "Desafios do cuidado: gênero, velhice e deficiência", problematiza o conceito de care (cuidado) na construção e na regulação dos vínculos em formas específicas e historicamente situadas, que encontram consensos e desenhos que estavam internalizados e foram repetidos na pandemia de covid-19. O exercício de cuidado também está permeado pelo conflito e pelas relações de poder. O conflito pode surgir pela incapacidade de atender à infinidade de necessidades existentes na obrigação e na inevitável seleção e priorização de uns requerentes pelos outros. É um processo complexo e não cabe retaliações aos que o conduzem de tal forma em meio à pandemia. E também caracterizado por contradições internas e frustrações, distante de um imaginário idealizado e romantizado que simplifica as variáveis que atravessam a todos em algum momento da vida (TRONTO, 1998). É importante destacar que o cuidado reclama "una apreciación empática de las emociones" (TRONTO, 1998, p. 19).

A própria dinâmica do cuidado está em constante modificação. José et al. (2016) expõe o conjunto de questões que marcaram a percepção de cuidado em diferentes décadas. Nos anos oitenta, o cuidado era pensado como uma relação unidirecional, na qual o cuidador era ativo e cuidava de um outro passivo e dependente. O outro era considerado incapaz de atender às suas próprias necessidades. $\mathrm{O}$ estresse do cuidador era $\mathrm{o}$ objeto central da reflexão, sem aprofundar as formas de existência na velhice na esfera pública, privilegiando as pesquisas na esfera privada. Posteriormente, a tendência das pesquisas de reconhecer a necessidade de redefinir o conceito de care se manteve nas duas décadas seguintes, consolidando os desenvolvimentos anteriores e o reconhecimento de que a relação de cuidado é baseada na interdependência e reciprocidade.

São os estudos sobre o capacitismo decolonial que passaram a exigir a revisão do corpo conceitual utilizado, em que a palavra "cuidado" deveria ser evitada, já que o conteúdo emocional nas análises inibia os 
projetos emancipatórios e de autodeterminação de pessoas cuidadas, homogeneizando, por exemplo, os idosos. A ideia de um sujeito unificado por uma identidade que se sobrepõe a outras práticas identitárias se sustenta numa situação em que as identidades ganham fluidez e envolvem uma tomada de decisão biográfica por parte de cada indivíduo.

Cuidado, portanto, à luz das formulações de Annemarie Mol em entrevista (MARTIN; SPINK; PEREIRA, 2018), é mais que uma política pública ou nicho de atuação médico-estatal. Trata-se de olhar para os elementos anteriores aos tradicionais centros de poder biomédico; que se iniciam na autopercepção, no olhar para si mesmo, nas relações em comunidade, nas memórias e tradições e, sobretudo, no reconhecimento de estratégias menores, marginalizadas e femininas como formas de amplificar o que seriam os cuidados.

\section{A DESPEDIDA}

Lydia passou as últimas semanas aguardando a segunda dose da vacina. Ansiosa para o desfecho, só tinha interesse que tudo se concluísse. Cerceada de sua autonomia, precisou repensar a proposta de deixar o casarão para que eu desenvolvesse um espaço de cultura voltado para uma oficina permanente de tecnologia do mamulengo.

No entanto, a pressão familiar e o desejo de poucos em manter o casarão fechado apenas para usufruírem da calçada durante as festividades de Santana venceu. Ela partiu com o filho para conhecer outros lugares do Brasil. Não foi um mau arranjo, mas deixou um gosto amargo na boca, principalmente quando vemos a casa fechada. A sensação incômoda é de que o colonialismo patriarcal branco, machista, misógino e velhofóbico venceu a peleja. Mas é só uma sensação, um ilusionismo próprio da lógica da subalternização dos corpos que nos faz acreditar que os espaços são mais importantes que as pessoas.

A agência dos objetos, por vezes, é mais forte que as pessoas, pois promovem ações de desestabilizações sutis, descentralizando as ações que indubitavelmente acreditávamos que poderiam partir somente dos humanos. Os mamulengos não foram embora de Caicó, eles se esparramaram! E a última oficina contaminou a todos, assim como era temido que acontecesse com o vírus.

Catarina Calungueira herdou a tecnologia e tomou para si a peleja. Lydia não habita mais no casarão porque ela é maior ${ }^{9}$.

\section{NOTAS}

1. Calungueira é uma nomenclatura derivada da palavra calungueiro, que, por sua vez, refere-se ao construtor dos bonecos de fantoche, o mamulengo (MACEDO, 2014, p. 14). Calungueira é outra forma de designar a mulher que constrói e anima o mamulengo.

2. Título da canção da banda Francisco, el Hombre (2013). “Triste, louca ou 
má" é uma tradução da expressão "sad, mad or bad", usada para denominar, de maneira pejorativa, mulheres que decidem ficar sozinhas.

3. Os fenótipos europeus que designam o tipo de pessoa que mora na região do Seridó tem a ver com o povoamento por famílias de cristão novos ou holandeses. Estas características também carregam narrativas de colonização e relações de poder (MACEDO, 2013; MACÊDO, 2005), pois escondem a presença negra no Seridó. O seridoense ser ativo, com olhos claros e que ostenta riquezas é mais uma das histórias que inviabilizam a diversidade étnico-racial e religiosa do Rio Grande do Norte.

4. Santiago Castro-Gomez e Ramón Grosfoguel (2007), Ramón Grosfoguel (2002, 2007, 2008, 2012), Walter Mignolo (2000a, 2000b, 2008), Arturo Escobar e Walter Mignolo (2010), Catherine Walsh (2004, 2007, 2009), Rita Laura Segato (2013, 2012, 2014), Eduardo Restrepo e Axel Rojas (2010).

5 Para Lia Vainer Schucman, a ideia de que toda a pessoa do grupo representa o grupo como um todo é um dos processos de racialização do outro, que é próprio da branquitude. O outro é um grupo, o outro é racializado, e nós brancos somos indivíduos, cada um representado por uma humanidade.

6. Os tapuias - termo utilizado pelos povos tupi do litoral para denominarem os povos "gentio brabo" do interior, também utilizado pelos portugueses - foram dizimados na Casa Forte do Cuó, na ribeira do Seridó, em Caicó (CAVIGNAC; MACÊDO, 2016).

7. Para Câmara Cascudo (1988), em seu Dicionário do Folclore Brasileiro, a palavra caapora pode ser a origem do conceito de caipira, ou seja: caá = mato; pora $=$ habitante, morador. Neste caso, é uma figura do folclore brasileiro, considerada a protetora dos animais e guardiã das florestas

9. Agradecemos aos avaliadores e aos organizadores do dossiê pelas sugestões, correções e críticas fundamentais para garantir a qualidade deste texto.

\section{REFERÊNCIAS}

AMARAL, Ana Maria. O inverso das coisas. Móin-Móin - Revista de estudos sobre teatro de formas animadas, Jaraguá do Sul: SCAR/Udesc, v. 1, n. 1, 2005.

BALARDIM, P.; RECIO, L. P.; DE OLIVEIRA, F. L. Uma arte desobediente. Móin-Móin - Revista de Estudos sobre Teatro de Formas Animadas, Florianópolis, v. 1, n. 22, p. 016-027, 2020.

BEAUVOIR, Simone. A velhice. Rio de Janeiro: Nova Fronteira, 1999.

BELTRÃO, Jane Felipe. Autonomia não se confunde com teimosia! Discriminação por idade em tempos de covid-19. Boletim cientistas sociais e o coronavírus, n. 26, 2020.

BOSI, Ecléa. Memória e sociedade. São Paulo: Companhia das Letras, 2010.

CARRARA, Sérgio. As Ciências Sociais e a Saúde Coletiva frente a atual epidemia de ignorância, irresponsabilidade e má-fé. Boletim cientistas sociais e o coronavírus, n. 3, 2020.

CASTRO-GÓMEZ, Santiago; GROSFOGUEL, Ramon (2007). Prólogo. Giro decolonial, teoría crítica y pensamiento heterárquico. In: CASTRO-GÓMEZ, Santiago; GROSFOGUEL, Ramon (coord.) El giro 
decolonial: reflexiones para uma diversidad epistêmica más allá del capitalismo global. Bogotá: Siglo del Hombre; Universidad Central, Instituto de Estudios Sociales Contemporáneos, Pontificia Universidad Javeriana, Instituto Pensar, 2007.

CAVIGNAC, Julie; MACÊDO, Muirakytan K. de. Tronco, ramos e raízes!: história e patrimônio cultural do Seridó negro. Natal: EDUFRN, 2016.

COHEN, Lawrence. No aging in India: the uses of gerontology. Culture, medicine and psychiatry, v. 16, p. 123-161, 1992.

DEBERT, Guita Grin; FÉLIX, Jorge. Dilema ético, os idosos e a metáfora da guerra. Folha de São Paulo, São Paulo, 19 abr. 2020.

DEBERT, Guita Grin; PULHEZ, Mariana Marques (org.). Desafios do cuidado: gênero, velhice e deficiência. 2. ed. Campinas: UNICAMP/ IFCH, 2019.

DEBERT, Guita Grin. A Invenção da terceira idade e a rearticulação de formas de consumo e demandas políticas. Revista Brasileira de Ciências Sociais, v. 12, n. 34, p. 39-54, 1997.

DOURADO, Simone P.D.C. A pandemia de covid-19 e a conversão de idosos em "grupo de risco". Cadernos de Campo, São Paulo: USP, v. 29, p. 153-162, 2020.

ESCOBAR, Arturo; MIGNOLO, Walter. Globalization and the decolonial option. Londres; Nova York: Routledge, 2010.

FEDERICI, Silvia. Calibã e a bruxa: mulheres, corpo e acumulação primitiva. Trad. de Coletivo Sycorax. São Paulo: Elefante, 2017.

GOLDENBERG, Mirian. A velhofobia está dentro de mim! Folha de São Paulo, São Paulo, 05 nov. 2020.

GROSFOGUEL, Ramón. Colonial difference, geopolitics of knowledge and global coloniality in the modern/colonial capitalist world-system. Review, Nova York, v. 25, n. 3, p. 203-224, 2002.

GROSFOGUEL, Ramón. From postcolonial studies to decolonial studies: decolonizing postcolonial studies - a preface. Review, Nova York, v. 29, n. 2, 2006.

GROSFOGUEL, Ramón. The epistemic decolonial turn: beyond political economy paradigms. Cultural Studies, v. 21, n. 2-3, p. 211-23, 2007.

GROSFOGUEL, Ramón. Para descolonizar os estudos de economia política e os estudos pós-coloniais: transmodernidade, pensamento de fronteira e colonialidade global. Revista Crítica de Ciências Sociais. n. 80, p. 115-147, 2008.

GROSFOGUEL, Ramón. Descolonizar as esquerdas ocidentalizadas: para além das esquerdas eurocêntricas rumo a uma esquerda transmoderna descolonial. Contemporânea - Revista de Sociologia da UFSCar, São Carlos, v. 2, n. 2, p. 337-362, 2012.

HENNING, Carlos Eduardo. Nem no mesmo barco nem nos mesmos mares: gerontocídios, práticas necropolíticas de governo e discurso sobre velhices na pandemia da COVID-19. Cadernos de Campo, São Paulo, v. 20, n. 1, p. 150-155. Disponível em: <https://www1. 
folha.uol.com.br/colunas/miriangoldenberg/2020/04/velhofobia. shtml $>$. Acesso em: 18 maio 2020.

HOUDART, Sofie. (2015). Humanos e não humanos na antropologia. Ilha, v. 17, n. 2, p. 13-29, 2015.

JOSÉ, José de São; BARROS, Rosanna; SAMITCA, Sanda; TEIXEIRA, Ana. Older persons experiences and perspectives of receiving social care: asystematic review of the qualitative literature. Health and social care in the community, v. 24, n. 1, p. 1-11, 2016.

MACEDO, Zildate Ramos de. "Show de Mamulengos" de Heraldo Lins: construções e transformações de um espetáculo popular. Tese (Doutorado em Antropologia Social) - Programa de Pós-Graduação em Antropologia Social da Universidade Federal do Rio Grande do Norte - PPGAS, UFRN, 2014.

MACEDO, Helder Alexandre Medeiros de. Outras famílias do Seridó: genealogias mestiças no sertão do Rio Grande do Norte (séculos XVIII-XIX). 360 f. Tese (Doutorado) - Centro de Filosofia e Ciências Humanas, Programa de Pós-graduação em História, UFPE, Recife, 2013.

MACÊDO, Muirakytan Kennedy de. A penúltima versão do Seridó: uma história do regionalismo seridoense. Natal: Sebo Vermelho, 2005. p. 67-8.

MARTIN, D., SPINK, M.; PEREIRA, P. Corpos múltiplos, ontologias políticas e a lógica do cuidado: uma entrevista com Annemarie Mol. Interface - comunicação, saúde, educação, v. 22, n. 64, p. 295-305, 2018.

MIGNOLO, Walter D. Local histories/global designs: coloniality, subaltern knowledge, and border thinking. Princeton: Princeton University Press, 2000a.

MIGNOLO, Walter D. La colonialidad a lo largo y a lo ancho: el hemisferio occidental en el horizonte colonial de la modernidad. In: LANDER, E. (Comp.). La colonialidad del saber: eurocentrismo y ciencias sociales. Buenos Aires: Perspectivas Latinoamericanas/CLACSO, 2000b. p. 34-52.

MIGNOLO, Walter D. Desobediência epistémica: a opção descolonial e o significado de identidade em política. Cadernos de Letras da UFF: dossiê literatura, língua e identidade, n. 34, p. 287-324, 2008.

MOLINIER, Pascale; PAPERMAN, Patricia. Descompartimentar a noção de cuidado? Revista Brasileira de Ciência Política, n. 18, p. 43-57, dez. 2015.

OLIVEIRA, Marcos Fernandes de. "O único Deus na terra para uma mulher é o seu marido": a produção de gênero no jornal "O Povo" e em processos-crimes do Seridó Potiguar (1880-1900). Dissertação (Mestrado em História) - Universidade Federal de Campina Grande, Centro de Humanidades, 2017.

PAIT, Heloisa. A vida dos "velhinhos", as conexões sociais e as lideranças institucionais. Boletim cientistas sociais e o coronavírus, n. 26, 2020.

PEREIRA, P.P.G. Queer decolonial: quando as teorias viajam. Contemporânea - Revista de Sociologia da UFSCar, São Carlos, v. 5, n. 2, jul./dez. 2015. 
RESTREPO, Eduardo; ROJAS, Axel. Inflexión decolonial: fuentes, conceptos y cuestionamientos. Popayán: Editorial Universidad del Cauca, 2010.

SEGATA, Jean. Covid-19: escalas da pandemia e as escalas da antropologia. Boletim cientistas sociais e o coronavírus, n. 2, 2020.

SEGATO, Rita Laura. Ejes argumentales de la perspectiva de la Colonialidad del poder. Casa de las Américas, v. 272, p. 1-5, 2013.

SEGATO, Rita Laura. Gênero e colonialidade: em busca de chaves de leitura e de um vocabulário estratégico descolonial. E-cadernos CES, v. 18, p. 1-5, 2012.

SEGATO, Rita Laura. El sexo y la norma: frente estatal, patriarcado, desposesión, colonidad. Revista Estudos Feministas, UFSC, v. 22, p. 593-616, 2014.

SILVA FILHO, Jorge Luiz Veloso da; PACHECO, Ricardo de Aguiar. Museu do Mamulengo na sala de aula: proposição de jogos educativos como recurso didático no ensino de história. 2020. Disponível em: <https://www.revistas.udesc.br/index.php/moin/article/ view/19294/12520>. Acesso em: 18 maio 2020.

SCHUCMAN, Lia Vainer. Entre o branco e a branquitude: letramento racial e formas de desconstrução do racismo. Portuguese Literary \& Cultural Studies, 2021.

TONIOL, Rodrigo. Cientistas sociais e o coronavírus. boletim cientistas sociais e o coronavírus, n. 1, 2020.

TRONTO, J.C. Uma ética de cuidado. Gerações: jornal da sociedade americana sobre envelhecimento, v. 22, n. 3, p. 15-20, outono 1998.

WALSH, Catherine. Colonialidad, conocimiento y diáspora afro-andina: construyendo etnoeducación e interculturalidad en la universidad. In: RESTREPO, Eduardo; ROJAS, Axel (ed.). Conflicto e (in) visibilidad: retos en los estudios de la gente negra en Colombia. Popayán: Editorial Universidad del Cauca, 2004. p. 321-346.

WALSH, Catherine. Interculturalidad crítica/pedagogia decolonial. In: WALSH, Catherine. Memórias del Seminário Internacional "Diversidad, Interculturalidad y Construcción de Ciudad”. Bogotá: Universidad Pedagógica Nacional, 2007. p.17-19.

WALSH, Catherine. Interculturalidade crítica e educação intercultural. In: SEMINÁRIO "INTERCULTURALIDAD Y EDUCACIÓN INTERCULTURAL". Conferência. Instituto Internacional de Integración del Convenio Andrés Bello, La Paz, Bolívia, 2009.

SUBMETIDO EM: 26/07/2021

APROVADO EM: 25/10/2021 